www.jmscr.igmpublication.org

Impact Factor (SJIF): 6.379

Index Copernicus Value: 71.58

ISSN (e)-2347-176x ISSN (p) 2455-0450

crossref DOI: _https://dx.doi.org/10.18535/jmscr/v6i2.109

Journal Of Medical Science And Clinical Research

\title{
Clinical Profile of Patients with Diabetic Foot Ulcer and Its Correlation with Neuropathy, Peripheral Vascular Disease and Glycemic Control
}

\author{
Authors \\ Dr Bilal Pathan ${ }^{1}$, Dr Raghav R Nagpal ${ }^{2}$, Dr Sandeep Rai ${ }^{3}$ \\ ${ }^{1,2}$ Resident, ${ }^{3}$ Professor \\ Department of Medicine, MGM Medical College, Navi Mumbai \\ Corresponding Author \\ Dr Bilal Pathan \\ Department of Medicine, MGM Medical College, Navi Mumbai
}

\section{Introduction}

Diabetes is one of the most prevalent chronic diseases. It is estimated that the annual Population based incidence of a diabetic foot ulcer ranges from $1.0 \%$ to $4.1 \%$. The lifetime Incidence may be as high as $25 \%$. $85 \%$ of Diabetes related amputations are preceded by foot ulcers, and it accounts for more than half of non-traumatic lower limb amputations. The vascular insufficiency and neuropathy accompanying the diabetic foot most often necessitate amputation of the limb. Diabetic foot is classified into 2 main types: NPU (neuropathic ulcer) and NIU (neuroischaemic ulcer). In NIU, PVD is also present in addition to neuropathy. Differentiation between NPU and NIU is important because they require different therapeutic strategies and their prognosis is different. Prevalence of PVD has been shown to be higher among patients with DM as compared to age and sex matched non diabetics. Neuropathy is a major contributing risk factor for foot ulcers and can involve both somatic and autonomic fibres. The myelinated (A-type) sensory fibres are associated with proprioception, sensation of light touch, pressure, and vibration, and motor innervations of the muscle spindles. Neuropathy of the A-type nerve fibre results in ataxic gait and intrinsic weakness of the foot muscles.

Neuropathy of the C-type sensory fibres is the loss of protective sensation; it results in the loss of pain threshold with prolonged and increased shear forces and repeated trauma. In addition, loss of protective sensation due to peripheral neuropathy is the most common cause of ulceration. In our study we undertook study of 50 patients of diabetic foot admitted in our hospital. Assessment of vascular status and neuropathy and analysis of risk factors responsible for development of diabetic foot ulcers and subsequent lower extremity amputation in patients of diabetic foot. We studied the correlation of diabetic foot ulcer with $\mathrm{HbA} 1 \mathrm{c}$ and glycemic control, incidence of peripheral vascular disease in diabetic foot patients and treatment outcomes of these patients in our hospital. 


\section{Materials and Methodology}

A cross-sectional hospital based study consisting of 50 consecutive adults diagnosed with diabetes having diabetic foot ulcers at MGM hospital, Kamothe. Adult patients of more than 18 yrs age with diabetes mellitus and having diabetic foot ulcer of wagner grade 1 to 4 were included in our study. Patients with age less than 18 yrs, venous ulcers, previous history of amputation, wagner grade 5 were excluded from our study. Institutional ethics committee clearance was obtained. History and clinical features of all the patients were recorded in detail. Detailed examination of the involved foot was done to assess the location, nature, extent of lesion, sensory and motor system involvement and vascularity of the limb. Foot deformity assessment was done and various parameters such as arthropathy, joint mobility, muscle wasting, hammer/claw toes were assessed.

Femoral, popliteal, dorsalis pedis and posterior tibial pulses were palpated on both sides to assess peripheral arterial status of all the patients and ankle-brachial index was determined. Values $<1$ were considered having peripheral vascular disease. Other investigations such as fasting blood sugar, hbalc, lipid profile were also done. Vibration sense, hot, cold sensations were tested in all patients by biothesiometry.

\section{Results}

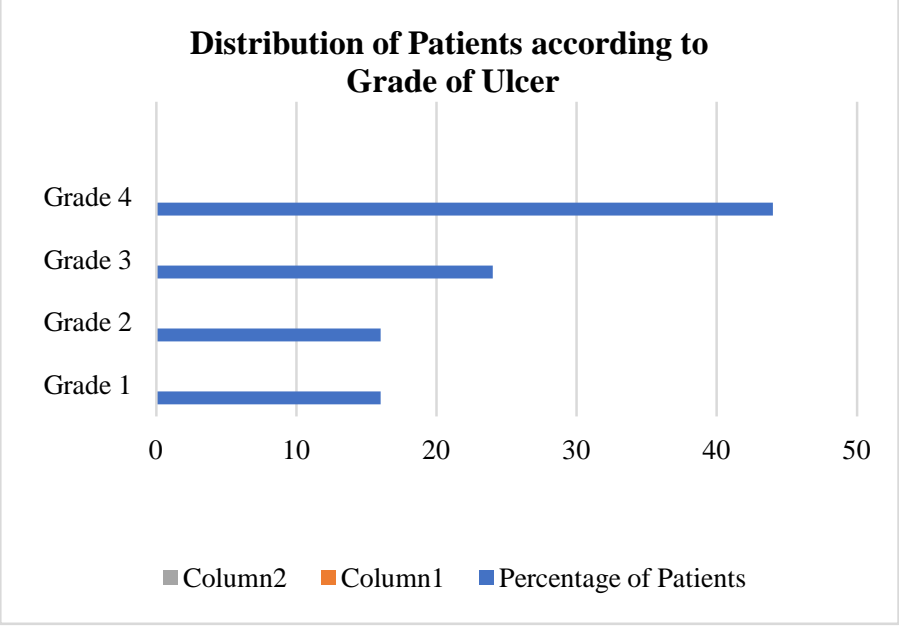

Distribution according to duration of Diabetes

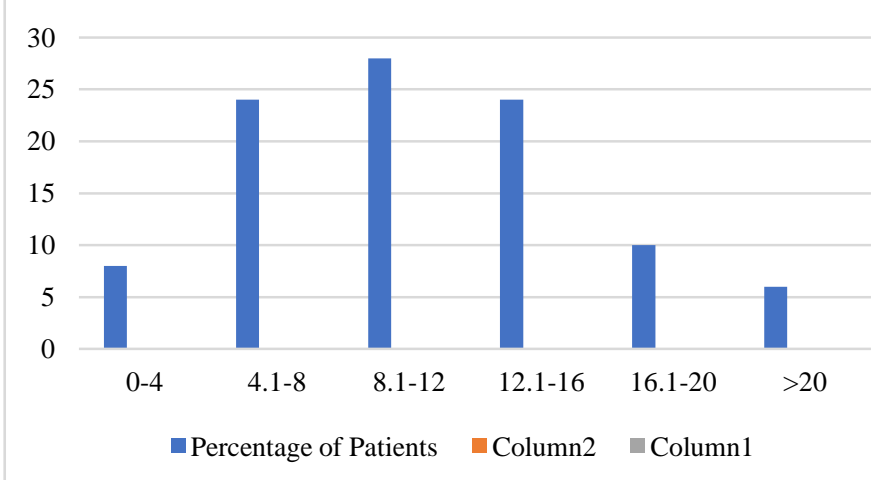

Distribution Acc to HbA1c

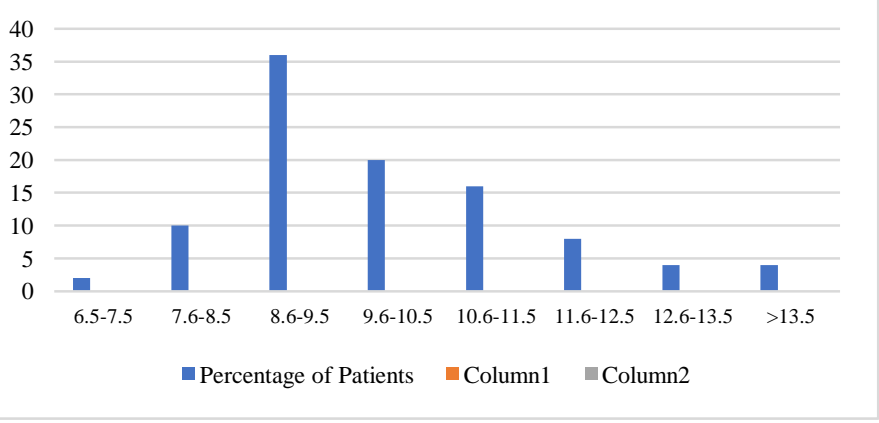

In our study the mean age of study subjects was $53.18+/-12.89$ yrs and male predominance was observed in study subjects with prevalence of male to female ratio as approximately 5.25:1. Most of the study population were farmers (54\%) followed by housewife (12\%) and business (12\%). $66 \%$ of study population had history of trauma and showing 35\% increased LDL, 24\% Hypertriglyceridemia, 16\% Hypercholesterolemia. $68 \%$ of diabetic foot ulcer patients had history of smoking. Although smoking provided a higher risk of PVD and for diabetic foot ulcers this did not reach statistical significance in our study .Femoral artery pulsations were present in all patients, popliteal artery pulsation (88\%), Posterior tibial (44\%), dorsalis pedis (36\%). Deformity was seen in diabetic ulcer patients, amongst them most common was limited joint mobility (8\%) and charcoat arthropathy $(8 \%)$.

Critical examination of ulcers for grading revealed that the percentage of grade 4 lesion was highest $(44 \%)$ followed by grade $3(24 \%)$. $28 \%$ of ulcers had duration of diabetes between 8.1 to 12 yrs, followed by $24 \%$ having a duration of 
diabetes between 4.1 to 8 yrs and 12.1 to $16 \mathrm{yrs}$. The mean duration of diabetes was $11.2 \mathrm{yrs}$. When grade of diabetic foot ulcers was compared with duration of diabetes, it was found that out of 22 cases of grade 4 diabetic foot ulcer, 7 were having duration between 12.1-16 years and 5 between 16.1- 20, while in grade 3 ulcer, 7 were having duration between 8.1- 12 years and 5 between 12.1-16 yrs. Maximum diabetic foot ulcers patients had duration between 8.1-12 yrs. $36 \%$ of ulcer had hba1c between 8.6-9.5, followed by $20 \%$ in hbalc between $9.6-10.5$. There is strong evidence of relationship between various grade of diabetic foot ulcers and hbalc. When grade of diabetic foot ulcers were categorized with hbalc levels, it was found that out of 22 cases of grade 4 diabetic foot ulcer, 8 were having hbalc between 10.6-11.5 and 6 between 9.6-10.5, while in grade 3 ulcer, 8 were having hbalc between 8.6-9.5 and 4 between 9.6-10.5. Maximum diabetic foot ulcers had hba1c between 8.6-9.5.

Males $(76 \%)$ had higher sign and symptoms of peripheral neuropathy as compared to females (24\%). The most common clinical presentation of peripheral neuropathy was Intermittent claudication14 (28\%), Parasthesia 13 (26\%) Numbness 11 (22\%). 33.33\%, 28.28\% and $22.22 \%$ of grade IV, III and II ulcer had peripheral neuropathy. There is strong relationship between various grade of diabetic foot ulcers and peripheral neuropathy ( $\mathrm{p}$ value 0.001 ). In this study, it was observed that $22.72 \%$ of diabetic ulcer patients with peripheral neuropathy had HBA1c between 9.6- 10.5 followed by $20.45 \%$ having HBA1c between 10.6 -11.5. In this study, it was observed that $25 \%$ of diabetic ulcer patients with peripheral artery disease had HBA1c between $10.6-11.5$ followed by $22.22 \%$ having HBA1c between. 9.6- 10.5. 38.88\% patients of stage 2 Peripheral artery disease (PAD) had Ankle Brachial Index (ABI) values 0.50 TO 0.80 , and 25 $\%$ of STAGE 3-Chronic Critical Ischemia had values 0.30 TO 0.50 . No relationship could be established between various grade of diabetic foot ulcers and PAD ( $\mathrm{p}$ value -0.198 ) in our study

\section{Discussion}

The majority of subjects had type 2 Diabetes. Similar $^{[4]}$ finding have been reported by other studies. In the present study, 52\% had ${ }^{[5,6]} \mathrm{BMI}$ above 30 which is similar to other studies. In present study Occupation of most of the patients was farming (54\%), which is consistent with findings of ${ }^{[6]}$ other studies. These findings may be attributed to scant knowledge of the disease and lack of care required to manage the disease and its complications, style of living in the villages and participation in farming and agricultural works and bare foot walking could be the reason for affecting this group of population the most. In present study, $66 \%$ of study population had a history of trauma. In diabetes mellitus, trauma to the foot plays a critical role in the evaluation of the disease process ${ }^{[7]}$. In a study done by Kunal Solanki et al, (54\%) patients gave a history of trauma to foot. In this study $68 \%$ of diabetic foot ulcer patients had a history of smoking. Smoking is an independent risk factor for increased risk of amputation ${ }^{[8-10][11]}$ in diabetic patients.

Viswanathan found that smoking increases the risk of DFU by reducing blood circulation in the legs and reducing sensation in the feet. The percentage of grade III and IV ulcers was higher in subjects habitual of smoking. Apart from PVD, most probably uncontrolled glucose level also delays ${ }^{[4]}$ wound healing and results in severity of ulcers. Studies have shown, that duration of diabetes, impaired pain perception, absent dorsalis pedis, and the presence of any retinopathy were significant predictors of ${ }^{[11]}$ the presence of foot ulcers. In the present study femoral artery pulsations were present in all patients, popliteal artery pulsation (88\%), Posterior tibial (44\%) and Dorsalis pedis (36\%). Several other studies have reported that foot deformities are important contributory risk factors by predisposing skin to high pressure ${ }^{[12,13]}$ at the site of the foot deformity. In this study, most common was deformity was limited joint mobility (8\%) \& Charcoat arthropathy $(8 \%)$. In a similar study ${ }^{[5,14]}$ done by Khalid Mahmood et al. patients had significant 
foot deformity. In the present study, Clinical examination of ulcers for grading revealed that the percentage of grade IV lesion was highest (44\%) followed by grades III (24\%). Similar findings were observed by by others 81 in which the majority of ulcer was of grade IV. Maximum diabetic foot ulcers patients had duration between $8^{[14]} 12$ years which is consistent with other studies. More commonly, long duration and poor metabolic control of diabetes are thought to be factors that increase ${ }^{[82]}$ the risk of chronic complications. There is strong evidence of relationship between various grades of diabetic foot ulcers and $\mathrm{HbA} 1 \mathrm{C}$. In present study, $36 \%$ of diabetic foot ulcer patients had HBA1c between $8.6-9.5 \%$. In another study, ${ }^{[14]} 90.52 \%$ patients had $\mathrm{HbA1c}$ level more than $8 \%$.It is clear that those patients, with high $\mathrm{HbA1c}$ levels have developed more severe grades of diabetic foot ulcers, reflecting that poor glycaemic control is also an important contributing factor. There is strong Correlation between various grade of diabetic foot ulcers and peripheral neuropathy. In the present study, males (76\%) had higher signs and symptoms of peripheral neuropathy as compared to females (24\%). The most common clinical presentation of peripheral neuropathy was intermittent claudication (28\%), paresthesia (26\%) and numbness. In another similar study, ${ }^{[10]}$ $(84.4 \%)$ patients had moderate to severe neuropathy. Also in other study, there ${ }^{[4]}$ were more than $75 \%$ of subjects with peripheral neuropathy. In a study done by ${ }^{[1]}$ Mohammad Zubair et al, neuropathy was observed in $50.6 \%$ of patients in diabetic foot ulcer patients. The pathogenesis of diabetic neuropathy includes various factors, like hyperglycemia, Vaso Nervorum, Protein Kinase C pathway activation, abnormal fatty acid metabolism, Myo-inositol, advanced glycated end product, antibody to ${ }^{[16-18]}$ neural tissue. In the year 2004, four major pathogenic pathways mechanism explaining the hyperglycaemic nerve damage were explained in a paper ${ }^{[19]}$ by Brownlee $M$ et al. These four major mechanisms are increased intracellular formation of AGEs, increased polyol pathway, activation of protein kinase $\mathrm{C}$ and increased hemosamine pathway flux. These are now accepted as major mechanisms for causation of Peripheral neuropathy. In the present study, it was observed that $25 \%$ of diabetic ulcer patients with peripheral artery disease. There was no relationship between various grades of diabetic foot ulcers and PAD ( $p$ value -0.198).

\section{References}

1. Wild S, Roglic G, Green A, Sicree R, King H (2004) Global prevalence of Diabetes : estimates for the year 2000 and projections for 2030. Diabetes Care 27: 1047-1053.

2. International Diabetes Federation (2012) The Global Burden. IDF Diabetes Atlas Fifth Edition.

3. Amos AF, McCarty DJ, Zimmet P, The rising global burden of diabetes and its complications: estimates and projections to the year 2010, Diabet Med 1997; 14 (5) $\mathrm{S} 1-\mathrm{S} 85$.

4. Shailesh K. Shahi, ; Surya K Singh , ; Sushil Kumar- Prevalence of Diabetic Foot Ulcer and Associated Risk Factors in Diabetic Patients From North India. The Journal of Diabetic Foot Complications, 2012; Vol 4, Issue 3, No. 4, Pages 83-91.

5. Ravishekhar Gadepalli- A Clinicomicrobiological Study of Diabetic Foot Ulcers in an Indian Tertiary Care Hospital care.diabetesjournals.org/content/29/8/172 7.

6. Nasser Janmohammadi, Mohammad Reza Hasanjani Roshan, Management of diabetic foot ulcer in Babol, North of Iran: an experience on 520 cases. Caspian J Intern Med. 2012 Summer; 3(3): 456-459.

7. Dr. Kunal Solanki, Dr. Hiren Parmar- The Surgical Management of Diabetic Foot. NJIRM 2010; Vol. 1(4).Oct- Dec.

8. Moss SE, Klein R, Klein BE. The 14-year incidence of lower extremity amputations in a diabetic population. The Wisconsin 
Epidemiolog Study of Diabetic Retinopathy. Diabetes Care 1999; 22(6)951-959.

9. Adler AI, Boyko EJ, Ahroni J, Smith DG. Lower extremity amputation in diabetes: the independent effects of peripheral vascular disease, sensory neuropathy, and foot ulcers. Diabetes Care 1999; 22:10291035.

10. Mayfield JA, Reiber GE, Nelson RG, et al. A foot risk classification system to predict diabetic amputation in Pima Indians. Diabetes Care 1996; 19(7):704-709.

11. Viswanathan V. The diabetic foot: perspectives from Chennai, South India. Int Low extrem Wounds 2007; 6: 34-6.

12. Reiber GE, Vileikyte L, Boyko EJ, del Aguila M, Smith DG, Lavery LA, et al. Causal pathways for incident lowerextremityulcers in patients with diabetes from two settings. Diabetes Care1999; 22:157-62.

13. De Sonnaville JJ, Colly LP, Wijkel D, Heine RJ. The prevalenceand determinants of foot ulceration in type II diabetic patients in aprimary health care setting. Diabetes Res ClinPract 1997; 35: 149-56.

14. Khalid Mahmood, S. Tehseen AkhtarClinical Profile and Management Outcome of Diabetic Foot Ulcers in a Tertiary Care Hospital .Journal of the College of Physicians and Surgeons Pakistan 2008, Vol. 18 (7): 408-412

15. Lavery LA, Armstrong DG, Wunderlich RP, Mohler MJ, Wendel CS, Lipsky BA. Risk factors for foot infections in individuals with diabetes. Diabetes Care 2006; 29: 12881293.

16. Polydefkis M, Griffin JW, Mcarthur J. New insights into diabetic polyneuropathy. JAMA 2003; 290(10):1371-1376.

17. Haslbeck KM, Schleicher E, Bierhaus A et al. The AGE/RAGE/NF-(kappa) B pathway may contribute to the pathogenesis of polyneuropathy in impaired glucose tolerance (IGT). Exp

Clin Endocrinol Diabetes 2005; 113(5):288-291.

18. Cameron NE, CottorMA. Metabolic and vascular factors in the pathogenesis of diabetic neuropathy. Diabetes 1997; 46(suppl 2):S31-S37.

19. Brownlee M. Biochemistry and Molecular cell biology of diabetic complications. Nature. 2001; 414: 813-820. 